\title{
Psychological Therapy for Postnatal Depression in UK Primary Care Mental Health Services: A Qualitative Investigation Using Framework Analysis
}

\author{
Holly Hadfield ${ }^{1} \cdot$ Suzanne Glendenning ${ }^{2} \cdot$ Penny Bee $^{3} \cdot$ Anja Wittkowski $^{1,2}$
}

Published online: 10 September 2019

(c) The Author(s) 2019

\begin{abstract}
Objectives Postnatal depression (PND) can have negative consequences for mother and infant. Current psychological therapies are effective in treating depression but improvements in mother-infant outcomes have not yet been established. We aimed to capture mothers' experiences of therapy for PND with a focus on parenting-related outcomes. We also sought their views on including parenting support within interventions.

Methods Fourteen mothers who received psychological therapy in the United Kingdom's National Health Service (NHS) participated in semi-structured interviews. Data were audio-recorded, transcribed, coded and analysed using Framework Analysis.

Results Three main themes were identified: 'The experience of therapy', 'Therapy outcomes' and 'Views about parenting interventions for postnatal depression'. The main themes were underpinned by other themes. Overall the findings revealed that mothers perceived therapy as helpful in improving mood, confidence as a parent and relationship with their infant. Mothers valued the process of normalising their experiences within group therapy and by their therapists because it reduced any shame and stigma associated with PND. Mothers thought parenting support within therapy would be acceptable if delivered collaboratively.

Conclusions Primary care-based psychological therapy for PND was perceived as helpful and acceptable. It clearly met some of the mothers' goals, especially if their beliefs about being a 'bad mother' was challenged and modified. Barriers to engagement, such as childcare issues and therapist's knowledge about perinatal mental health, would also need to be overcome. Finally, mother-infant interventions should be further explored as an adjunct treatment option.
\end{abstract}

Keywords Parenting $\cdot$ Mother-infant outcomes $\cdot$ Primary care mental health $\cdot$ Group therapy $\cdot$ Perinatal mental health, Service user experience

Postnatal depression (PND), a serious health concern for both mother and infant, is defined as an episode of depression that occurs in the first year after the birth of a child (O'Hara and McCabe, 2013). In PND the impact of

Anja Wittkowski

anja.wittkowski@manchester.ac.uk

1 Division of Psychology and Mental Health, The University of Manchester, Manchester, UK

2 Greater Manchester Mental Health NHS Foundation Trust, Manchester, UK

3 Division of Nursing, Midwifery and Social Work, The University of Manchester, Manchester, UK depression is complicated by additional caring responsibilities, disturbances in the mother-infant-relationship and adverse outcomes for the infant's cognitive and emotional development (Junge et al. 2017; O'Hara and McCabe 2013). PND can have a detrimental impact on maternal parenting behaviour (Letourneau et al. 2012; O'Hara and McCabe 2013); for example, it has been observed to negatively affect maternal sensitivity and responses towards the infant (Hipwell et al. 2000), and has been associated with increased hostility (Cornish et al. 2008). Perinatal depression on the whole is estimated to cost the United Kingdom (UK) $£ 22,360$ per mother and $£ 51,462$ per child (Bauer et al. 2015). The Department of Health (DH) has published their Five Year Forward View for Mental Health in 2016 with plans to increase funding for perinatal mental 
health services by $£ 365$ million over five years, supporting an additional 30,000 women. These plans present an ideal opportunity to develop new or refine existing psychological therapies which effectively address PND, both in terms of symptom reduction and improved parent-child outcomes (Dennis 2017; Dennis and Hodnett 2007; O'Hara and McCabe 2013).

In the UK, guidelines from the National Institute of Health and Care Excellence (NICE) suggest treating mild PND with guided self-help and moderate to severe PND with a high intensity intervention including CognitiveBehavioural Therapy (CBT; NICE, 2014). In primary care services in England, mild to moderate depression is typically treated in Improving Access to Psychological Therapy (IAPT) services following referral from a General Practitioner (GP) or via self-referral (Radhakrishnan et al.2013). Based on the NICE guidelines (2014), this typically involves 6-12 sessions of CBT, which focuses on behavioural activation and cognitive restructuring (Beck et al. 1979; Bower and Gilbody 2005).

Both individual and group-based psychological interventions have been shown to be effective in reducing symptoms of depression (Cuijpers et al. 2008; Dennis and Hodnett 2007; Scope et al. 2013). Historically, psychological therapies for PND have focused on depression symptoms and less on mother-infant outcomes, including the mother-infant-relationship or the infant's development (e.g., see Tsivos et al. 2015). Evaluations of parent-child outcomes indicate that traditional psychosocial and psychological therapies for PND do not lead to significant improvements in these areas, even when symptoms of PND have improved (Cooper et al. 2003; Cooper et al. 2010; Tsivos et al. 2015).

Conversely, although interventions that specifically target the mother-infant-relationship, such as mother-infantpsychotherapy, have demonstrated effectiveness in improving maternal parenting behaviour and child developmental outcomes (Nylen et al. 2006), their impact on the mothers' symptoms of depression was less clear. There has been a lack of research into the effects of psychological therapy for PND on both maternal mood and mother-infant outcomes. Given that many of the sequelae of PND relate to parent-child outcomes as well as maternal wellbeing, it is important that research and interventions explore all of these aspects (Cooper et al. 2010).

Consequently, researchers in the field of maternal mental health have proposed that new approaches to treating PND are necessary to meet the needs of mothers with this complex mental health problem (Dennis 2017; O'Hara and McCabe 2013). A programme combining brief CBT skills with parenting skills training (Baby 'Triple P'; Sanders 2012) was found to lead to nonsignificant improvements in maternal mood as well as subjective bonding in a pilot study, and the intervention was rated as highly acceptable to mothers (Tsivos et al. 2014). An intervention like Baby Triple $P$ was also viewed as acceptable by mothers with severe mental health difficulties admitted to an inpatient Mother and Baby Unit (Butler et al. 2014). Thus, therapies for PND which also address the mother-infant-relationship are a promising area of research.

In-depth understandings of service users' experiences are an important component of mental health research and intervention development (Levitt et al. 2006). Qualitative research into the experience of PND highlights themes of unmet maternal expectations, isolation, vulnerability, loss of identity and views of the self as a 'bad' parent (Beck 2002; Mollard 2014). Metasyntheses of qualitative research report that psychological and psychosocial interventions for postnatal mental health difficulties can be difficult for mothers to access due to barriers including stigma, poor healthcare experiences and childcare issues (Hadfield and Wittkowski 2017; Megnin-Viggars et al. 2015). However, these interventions were generally found to be acceptable and beneficial, with particular value placed on the relationship with the therapist, feeling listened to without judgement, and receiving information on PND and parenting (Hadfield and Wittkowski 2017). Studies of mothers' treatment preferences have highlighted the importance of focusing on maternal cognitions and improving social support (O'Mahen et al. 2012) as well as providing the opportunity to have experiences validated (Dennis and Chung-Lee 2006). However, fewer studies have explored in depth the experience of specific psychological intervention techniques for PND, such as those used in CBT; the 'active ingredients' of therapy are less well understood (Hadfield and Wittkowski 2017; O'Hara and McCabe 2013). Furthermore, Hadfield and Wittkowski (2017) identified that hardly any qualitative studies had explored mothers' views on the inclusion of parenting-related aspects to the therapy they received for PND.

Therefore, the aim of this study was to explore mothers' experiences of psychological interventions for PND in UK NHS primary care mental health settings. A particular focus was on the perceived impact of current psychological therapies on parenting-related outcomes such as the motherbaby-relationship and parenting confidence. We also aimed to elicit mothers' views on including parenting support in a therapeutic intervention for PND. Our research questions were: (1) How did mothers experience primary care mental health interventions for PND? (2) Did mothers believe that these interventions adequately met their mental health needs as parents of young infants? (3) What were mothers' views on including parenting-based approach in their treatment for PND? 


\section{Method}

\section{Participants}

Participants were included if they were mothers of a healthy infant under two years old and had received psychological therapy for PND (as the main focus) within primary care mental health/psychology services in the NHS in the last two years. IAPT services were the main target setting because they predominantly provide NICE recommended CBT for depression, including PND (NICE 2014). All consenting participants provided basic demographic information and were asked questions using a semi-structured interview schedule, developed in conjunction with a researcher experienced in qualitative methodologies and in consultation with the University's Community Liaison Group to ensure acceptable questions were asked.

A convenience sample of 14 participants was interviewed. Eight participants were first-time mothers. Table 1 illustrates the demographic details of each participant, including the recruitment source. Participants were recruited from various locations across England. The average age of the participants was 32 years and most participants were married. Mothers recruited through the NHS had completed therapy in the last six months and mothers recruited through other routes had finished therapy in the last two years. All participants had received therapy, which focussed on PND as the target problem, in their local NHS primary care mental health service. Thirteen participants accessed therapy based on CBT and one participant received Eye Movement Desensitisation and Reprocessing (EMDR) after their initial assessment indicated that her PND was related to an earlier traumatic experience. Parenting was not generally a topic included in therapy. Eight participants had received group therapy and six had received individual therapy. Group therapy interventions comprised of six sessions of two hours in length. The number of individual sessions was approximately 12. Twelve participants had received some form of therapy before. Three of these participants had accessed therapy privately and one participant had received psychotherapy during their own professional training. In these cases, participants were asked to focus on their NHS therapy for PND during their interview.

\section{Procedure}

Ethical approval was sought to recruit participants through NHS services and through charities and social media. Local collaborators (e.g. clinical psychologists and cognitive behaviour therapists) were identified to facilitate recruitment using convenience sampling and to approach potential participants, who gave their consent to be contacted by the main researcher $(\mathrm{HH})$.

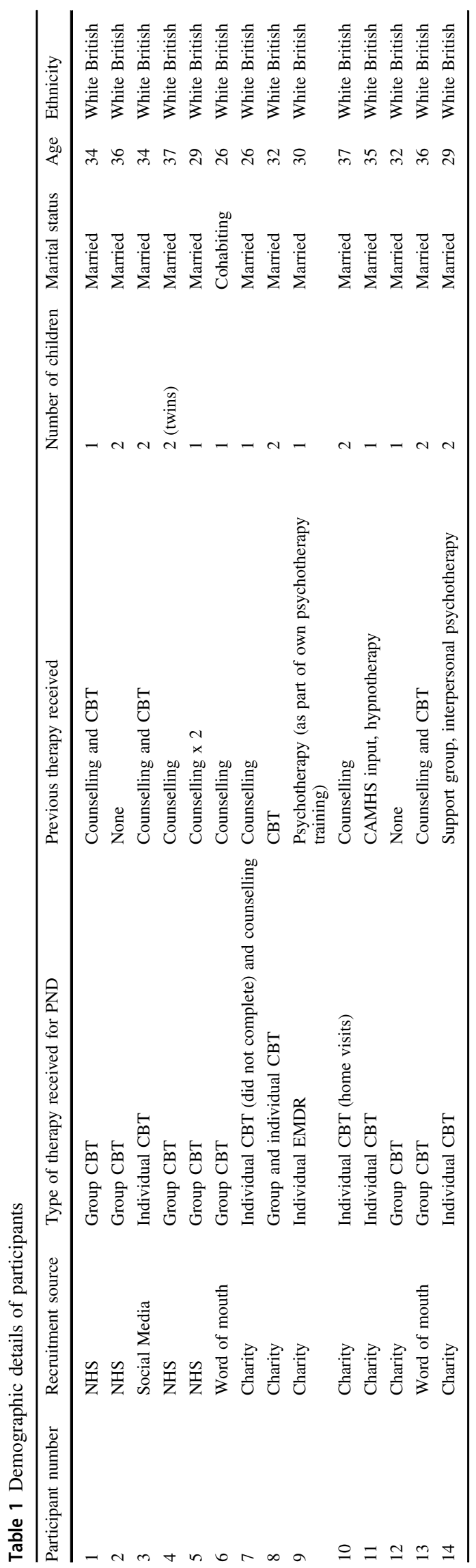


Table 2 Superordinate themes, themes and subthemes developed in the framework analysis

\begin{tabular}{|c|c|c|}
\hline Superordinate theme & Theme & Subtheme \\
\hline \multirow{3}{*}{$\begin{array}{l}\text { 1. Experience of therapy for } \\
\text { postnatal depression }\end{array}$} & 1.1 Hopes for therapy & \\
\hline & $\begin{array}{l}1.2 \text { Overall impressions of } \\
\text { therapy }\end{array}$ & \\
\hline & $\begin{array}{l}\text { 1.3 Important aspects of therapy } \\
\text { 1.4 Ending therapy }\end{array}$ & $\begin{array}{l}\text { 1.3.1 Practicalities } \\
\text { 1.3.2 Therapeutic techniques } \\
\text { 1.3.3 Supportive } \\
\text { relationships } \\
\text { 1.3.4 Acceptance of my } \\
\text { experience }\end{array}$ \\
\hline \multirow[t]{2}{*}{ 2. Therapy outcomes } & 2.1 Intrapersonal changes & $\begin{array}{l}\text { 2.1.1 Changes to mood } \\
\text { 2.1.2 Changes to cognition }\end{array}$ \\
\hline & 2.2 Interpersonal changes & $\begin{array}{l}\text { 2.2.1 Changes to the mother- } \\
\text { infant relationship } \\
\text { 2.2.2 Changes to the infant }\end{array}$ \\
\hline 3. Views about parenting in therapy & $\begin{array}{l}\text { 3.1 Advantages to including } \\
\text { parenting in therapy } \\
\text { 3.2 Disadvantages to including } \\
\text { parenting in therapy }\end{array}$ & \\
\hline
\end{tabular}

The study was also advertised on social media platforms (Facebook, Instagram and Twitter) using a poster, inviting interested participants to contact the researcher directly. The study was also advertised by charities the PANDAS Foundation and MIND via their own communications, and interested participants contacted the researcher via email. Interviews were conducted at the participant's home address or over the telephone, and information sheets and consent forms were posted ahead of the interview.

Confidentiality and the process of audio-recording were explained to participants, and written informed consent was obtained before proceeding. Interviews followed a topic interview guide and lasted between 30 and $75 \mathrm{~min}$. Interviews were audio-recorded and later transcribed, removing all identifying information.

\section{Data Analysis}

Data were analysed using framework analysis (Ritchie and Spencer 1994), a realist method of qualitative analysis within the family of thematic analysis (Gale et al. 2013; Ritchie and Spencer 1994). A major advantage of framework analysis over other qualitative methodologies is its ability to answer specific research questions, particularly relevant in applied research to inform policies and clinical practice (Ward et al. 2013). Five stages of analysis take data from line-by-line codes to a working framework which encapsulates themes, including defining concepts, finding associations and developing explanations (Ritchie and Spencer 1994). A key component of framework analysis also includes looking for negative cases (Furber 2010; Ward et al. 2013). Throughout the analysis, the reflexive position of both researchers was considered, including the impact of their life experiences and professional orientations on the interpretations of the data (Berger 2015). A reflection diary was used by the main researcher $(\mathrm{HH})$ to promote reflexivity.

\section{Results}

The framework analysis conducted yielded thematic content which was best delineated into three conceptual layers: these were described as superordinate themes, themes and subthemes. Although framework analysis usually describes the use of themes and subthemes (Gale et al. 2013), for greater clarity, it was decided to use the concept of 'superordinate' themes in addition to themes and subthemes to represent this, as in thematic analysis (Braun and Clarke 2006). The three superordinate themes were 'the experience of therapy for postnatal depression', 'views about parenting in therapy' and 'therapy outcomes'. The themes are illustrated in Table 2 and described in detail below, with reference to existing literature throughout.

\section{Experience of Therapy for PND: Hopes for Therapy}

In terms of hopes for therapy, 12 of the participants had received psychological therapy before the current study. Most women had had counselling previously, but were offered CBT in relation to their PND. Some mothers reported that their previous experiences of engaging in therapy shaped their expectations for the upcoming therapy for PND: 
I just hoped, even at that point, I was a great believer in talking therapies because I'd had talking therapies before and other types of therapy, so I sort of knew it was roughly about, it would look at how I was. (Participant 3 , individual CBT, $2^{\text {nd }}$ time mother).

Mothers talked about hoping that therapy would improve their mood, and particularly referred to hopes about taking a proactive role in 'feeling better', in learning new skills or strategies and increasing control over their mental health now and in the future.

I was just looking for ways to manage it really you know instead of digging myself into a hole with it I was looking for ways I could manage it myself [...] like different techniques I could pick up. (Participant 13 , group CBT, $2^{\text {nd }}$ time mother).

\section{Experience of Therapy for PND: Overall Impressions of Therapy}

All the mothers in the study believed that their therapy had been helpful or beneficial in some way. This finding is comparable to research reporting that psychological therapy for PND is generally effective (Dennis and Hodnett 2007; O'Hara and McCabe 2013). Mothers who had initially had reservations about group-based therapy reported that they found the format much more beneficial than expected and now preferred this format to the idea of individual therapy. Group therapy for PND has been reported to be acceptable to mothers in a previous qualitative systematic review (Scope et al. 2012). However, some disadvantages were identified in the present study. The group size often resulted in fewer opportunities for all mothers to share experiences, and the benefits of the group depended on the amount mothers were willing to share. Having experiences which were different to the rest of the group members left one mother feeling as though she did not belong in the group (P1). Perceived group belonging has been identified as a key factor in the process of group therapy (Kivlighan and Mullison 1988).

I was a bit intimidated - intimidated's [sic] the wrong word I was a bit hesitant at first because I thought oh my God I've gotta sit in front of a bunch of other people and talk about the problems I was having, you know what are they gonna think of me, but it actually ended up being better for me being in a group (Participant 5, group CBT, $1^{\text {st }}$ time mother).

The finding that the group format for CBT was acceptable in the current study suggests that the advantages and disadvantages of attending a group, as well as previous clients' experiences, should be discussed with potential attendees. Little research has directly compared the effectiveness or acceptability of group CBT to individual CBT for PND, or indeed depression in general, although it has been reported to be more effective than treatment as usual (Scope et al. 2013).

\section{Experience of Therapy for PND: Important Aspects of Therapy}

\section{Practicalities}

One of the key facilitators of engagement in therapy was the provision of childcare. Crèche was provided for mothers attending group therapy, and was cited as a valued aspect of the group sessions. Mothers in individual therapy valued flexibility in appointment times so that they could arrange childcare accordingly. Lack of childcare has been reported as a significant barrier for mothers accessing therapy for PND (Goodman 2009; O'Mahen and Flynn 2008). Attending group therapy was the first time many mothers had left their infant with another person, which was perceived as both anxiety-provoking and helpful in providing an opportunity to practise separation. All infants in the study were under 24 months old and most were under 12 months old.

It was useful to get the break away from $[\mathrm{X}]$ my little boy as well, so for him to be in the crèche, that was quite a big thing for me to do because I'd never really given him to anybody. So to hand him over was quite a big thing, and I think it probably helped prepare me for when he went to nursery actually so I think that was really useful (Participant 1 , group CBT, $1^{\text {st }}$ time mother).

Mothers also experienced emotional barriers to attending therapy. Some mothers reported that the guilt at the prospect of leaving their baby made attending therapy difficult. For others, the symptoms of PND were a barrier to attending, in particular low levels of motivation. There was often an interaction between low motivation or guilt and practical factors such as distance or ease of travel.

Cause it's like some days, obviously when I'd be having a bad day, and I'd be thinking oh I don't wanna go out I've gotta get them ready, I've gotta get them in the car, and I've gotta get the pram together to get there and I just didn't want to. 'Cause I thought being so far away it was too much time and effort to get there (Participant 5, group CBT, $1^{\text {st }}$ time mother). 
Whilst impaired motivation and practical considerations, such as time commitments, have been documented as barriers to attending therapy for depression more generally (Mohr et al. 2010), higher levels of guilt in leaving the infant to attend therapy appear to be a barrier specific to PND. Furthermore, although guilt at leaving an infant is considered to be a normal process in the adjustment to motherhood, intense guilt is recognised as a key factor in PND (Liss et al. 2013).

\section{Therapeutic techniques}

Most of the mothers received interventions based on CBT, and reported that they found the concept of challenging their thoughts helpful. It has been well documented that mothers with PND typically view themselves as 'bad' mothers and experience high levels of self-criticism in relation to their parenting (Beck 2002; O'Hara and McCabe 2013). Perceived failure to conform to prominent societal ideals around motherhood has been found to be a significant factor in PND (Henderson et al. 2016). Many mothers perceive the experience of PND as a further sign of failure as a mother, believing they should be able to 'cope' (Beck 2002). Mothers in the present study found challenging commonly experienced cognitions of being a 'bad mother' beneficial. The particular focus on maternal identity-related cognitions was also reported in a qualitative study of pregnant women and mothers' potential treatment preferences in CBT for PND (O'Mahen et al. 2012). Thought challenging was a novel concept for mothers in the current study and they reported surprise at its effectiveness.

I found it [thought challenging] very easy and I kind of thought it gave me a good explanation for why I was feeling that way, and it kind of put it into more of a, not a scientific context but it took it, it took the onus away from me - it didn't feel like it was my fault then, this was something that happened to lots of people and there are reasons for it, it depersonalised it in a way (Participant 12, group CBT, $1^{\text {st }}$ time mother).

Findings regarding the value of specific therapeutic techniques for various mental health difficulties have been mixed (Ahn and Wampold 2001). However, a common theme in the literature, echoed in the current findings, is the importance of increasing understanding of thoughts, feelings and behaviour as mechanisms of change (Levitt et al. 2006). Slade et al. (2010) also reported that mothers found identifying thought patterns helpful in CBT for PND. The current findings suggest that cognitive techniques had particular value for cognitions relating to being a mother in the context of PND, corroborating the notion that this is a key aspect of the PND experience. CBT techniques were found useful if they were delivered or presented in an open, collaborative manner.

Many mothers reported that the usefulness of cognitive techniques was enhanced through the use of 'homework', such as completing diaries. Completing diaries helped mothers to challenge unhelpful thoughts about themselves and improve their mood between sessions. This finding is in line with the experiences of CBT and its techniques more generally (Levitt et al. 2006; Staarup and Poulsen 2015). Behavioural homework tasks were also found to be helpful; for example, increasing self-care related activities, or achieving a specific goal. Interestingly, while in CBT behavioural tasks typically focus on increasing activity (Beck et al. 1979), mothers in the current study sometimes described homework goals of doing less. Doing more activities with their infants may be related to mothers' perceived need to be viewed as 'perfect' and 'coping well' (Henderson et al. 2016).

Yeah we did that you know that worrying thing, it was homework that you were supposed to try it out and you had to come back with like a goal that we were gonna achieve by the next week and then we had to come back and report back on how that went (Participant 2, group CBT, $2^{\text {nd }}$ time mother).

However, the additional time and effort required to complete homework, increased feelings of being overwhelmed in some mothers. This finding was reported by Barnes et al. (2013) in relation to service users with various mental health difficulties, but may have been particularly salient for mothers of young infants, because childcare responsibilities felt all-encompassing. Having tasks which fitted into the mother's current routine and that mothers knew were not mandatory were helpful in managing the sense of commitment.

I think the, 'cos you feel like every things so tiring as it is with depression, doing board work and lots of home work when you got home just felt like something added to that stress that you didn't need (Participant 7, individual CBT and counselling, $1^{\text {st }}$ time mother).

On the other hand, a smaller number of mothers in the study did not perceive a cognitive-behavioural approach to be appropriate for their needs. In contrast to the collaborative experience most mothers reported, one mother likened the approach to "being in school" which led to her terminating therapy and starting counselling instead (P7). One mother reported finding thought challenging difficult (P8). Another mother believed that while CBT was useful to an 
extent, it did not address some of the 'deeper seated' aspects of PND that some mothers might experience.

So at the time [CBT] was extremely helpful because I was lacking support and needed to feel like I was being looked after, so I think it did help me and it was very important but I don't think, I think now I can say it hasn't been the thing that has really helped me [...] It's more like thinking positively isn't it it's almost like you're, you're sort of trying to teach yourself to be more positive to see it in a different way, but I don't think it touches on really deep seated emotional problems that people might have that causes depression (Participant 14, individual CBT, $2^{\text {nd }}$ time mother).

\section{Supportive relationships}

The importance of the therapeutic relationship is widely established in psychological literature (Nilsson et al. 2007) and mothers in this study universally valued the experience of this supportive relationship. Mothers reported that a 'goodness of fit' with the therapist's personality facilitated them being more open in therapy. The key factors within the therapeutic relationship identified here have been acknowledged across other mental health difficulties as well as in women with PND (Hadfield and Wittkowski 2017; Noyce and Simpson 2016).

I: How important do you think the therapeutic relationship is in a therapy for postnatal depression?

$\mathrm{P}$ : well really important because if you go to a session and you feel like you don't get on with that person, or they're judging you or you just don't have a rapport with them, then you're not gonna bother are you (Participant 4 , group CBT, $2^{\text {nd }}$ time mother).

Overall, the therapeutic relationship was thought to have a substantial impact on the perceived success and outcomes of the mothers' intervention (Lambert and Barley 2001). This seemed particularly pertinent for mothers receiving individual interventions. These mothers reported feeling cared for by their therapist, an experience also reported by Myors et al. (2014), and described by mothers in therapy for PND in one study as "mothering the mother" (Bilzsta et al. 2010 , p. 50). This experience was not evident in the narratives of mothers in group therapy. Whilst the therapeutic relationship appears crucial in therapy in general, the building of a supportive therapeutic relationship appeared particularly vital to participants due to the nature of PND and the isolation the mothers experienced after having a child (Beck 2002).
Mothers who received group therapy found the relationships developed with group members one of the most helpful aspects of attending a group. They reported that they had established continuing support networks with group members. The value of supportive peer relationships corroborates mothers' treatment preferences as reported by Dennis and Chung-Lee (2006) and the sense of community that was highlighted in a metasynthesis of experiences of group therapy for PND (Scope et al. 2012). Yalom (1995) theorised that other members are the main mechanism of change for group therapy participants across mental health difficulties. Furthermore, levels of social support have been identified as a predictor of PND (O'Hara, Wisner and Asher 2014), and qualitative studies of PND identify isolation as a key experience (Beck 2002; Mollard 2014). Three mothers reported some difficulties in their relationship with their therapist, and this impacted on their experience of the therapy as a whole.

I ended up making a really good friend out of the group, erm, so to me I did find that the group helped but then meeting [friend] was really really good [...]. We speak to each other nearly every day, and if we're struggling then we talk to each other about it, so it, having that support there of someone who kind understands what you're talking about (Participant 1, group CBT, $1^{\text {st }}$ time mother).

\section{Acceptance of my experience}

A prominent theme across the participants' narratives was the value of having their experiences listened to, validated and understood without judgement. This is a common finding in the experience of psychological therapy in general (Levitt et al. 2006) and was also reported by a qualitative systematic review of 40 studies of treatment preferences for PND (Dennis and Chung-Lee 2006). Whilst acceptance appeared to be integral to the formation of a good therapeutic relationship, it also had additional separate benefits. For mothers in this study, acceptance (including from other mothers in group therapy) helped to normalise their experiences and appeared to reduce some of the shame and stigma surrounding PND (McLoughlin 2013). Furthermore, having their experiences normalised and accepted challenged participants' beliefs about being a bad mother (Beck 2002). Davies and Jasper (2004) also reported that social comparison appeared to be a key factor in the experience of group CBT for PND. Mothers with PND often report comparing their experiences against 'idealised' others and 'perfect' mothers (Bilzsta et al. 2010; Henderson et al. 2016). While mothers valued validation from a 
professional with relevant expertise, experiential understanding of the problem from other mothers in the group interventions meant that their feedback and support was often ascribed more value.

\section{Experience of Therapy for PND: Ending Therapy}

Mothers shared that ending therapy was a potentially anxiety-provoking time. This was a common finding in a metasynthesis of 17 studies of psychosocial and psychological interventions for PND (Hadfield and Wittkowski 2017). Ending therapy was described as the loss of a safety net by mothers in this study, as well as by mothers in Myors et al's study (2014). The level of follow up and opportunities for continued support varied. Mothers who believed support continued to be available felt more at ease about ending. Social support has been identified as an important factor in the prevention of, and recovery from, PND (Dennis et al. 2009; Dennis and Letourneau 2007). For mothers in group therapy, continuing friendships with other group members formed part of this support.

They signposted us back to [service] you know if you need further help, you can contact them, but had I not met these group of ladies I would have felt on my own (Participant 13, group CBT, $2^{\text {nd }}$ time mother).

\section{Therapy Outcomes: Intrapersonal Changes}

\section{Changes to mood}

All mothers in the study reported positive changes to their mood and quality of life following therapy.

So I definitely feel more happy and more positive, and I'm doing a lot more things for myself and I feel like our family and home life is a lot happier than it was before I did group (Participant 4, group CBT).

These findings are comparable to improvements reported in quantitative studies on the effectiveness of CBT for symptoms of PND (Dennis and Hodnett 2007; Stephens et al. 2016). Mothers believed that they had learnt psychological strategies to challenge negative thoughts and therefore manage their low mood, which would help protect their mental health in the future - this reflected the hopes they had for therapy initially.

It's really funny, it's probably not gonna go away, so I feel the tools she's given me are really gonna help if I, you know, have moments in my life where that, I feel that way again, I can, I can go back to it really (Participant 10, individual CBT).

\section{Changes to Cognition}

Mothers reported their thoughts had become less negative and more balanced. In the main, participants reported that they no longer believed they were a 'bad mother' and had greater confidence in their parenting abilities, beginning to recognise their strengths.

I feel like a much more capable mum now, even though what I do is no different to what I was doing back then (Participant 1, group CBT).

Not dwelling on all the negatives that I might feel, and she really made me see the little things that actually were big things that I'd done in life, so, yeah, I think it made me a very different, you know, person (Participant 7, individual CBT and counselling).

While reduction of self-critical beliefs and more balanced thinking is common following CBT for depression (Farabaugh et al. 2015), it is important to note that in PND, mothers typically must continue engaging in caring for their infant which may trigger their self-critical beliefs. Mothers must also manage the societal pressures of meeting idealised standards of motherhood (Henderson et al. 2016). Although CBT has been reported to be effective in reducing mood related symptoms of PND in several trials (Stephens et al. 2016), the evidence of the impact of CBT on maternal confidence and cognitions has been equivocal (O'Hara and McCabe 2013). However, this study is one of the first to explore in depth the perceptions of specific therapeutic techniques, such as thought challenging, and their impact on beliefs related to parenting confidence and identity as a mother and, as such, generated novel findings.

\section{Therapy Outcomes: Interpersonal Changes}

\section{Changes to the mother-infant-relationship}

Many of the mothers in the study believed that their relationship with their infant had improved since receiving therapy and were more able to enjoy their time with their infant, or were spending more time with them. Some attributed this to the improvements in their mood or selfcare. Other mothers observed they were experiencing less resentment, anger or frustration towards their infant, and so were responding to their babies more calmly.

Yeah, yeah, erm, our relationship's so much different now, I mean I did, I loved her from the day she was born, but I think I had a lot of resentment [...] whereas 
now, I love, I love just you know, cuddling up to her and just you know making sure she's ok now, it's completely different (Participant 7, individual CBT and counselling).

One meta-analysis reported depressed mothers to be more irritable and hostile, less engaged and warm, and play less with their infants (Lovejoy et al. 2000). The current findings appear to suggest that mothers experienced improvements in these areas. While improvement in relationships is often a common outcome of CBT in general, this may be particularly important for mothers given the implications for the physical care and psychosocial development of their young infants. In contrast, three mothers did not report changes in their relationship with their baby, because there had never been any difficulties perceived in this relationship prior to the therapy.

I don't think I had a bad relationship with him anyway... I don't think the depression was anything to do with him as such (Participant 1, group CBT).

The extent to which CBT and other psychotherapies address parent-child aspects of PND has been questioned (O'Hara and McCabe 2013). In a systematic review of 19 studies, psychological therapies were not found to have a significant impact on mother-infant-relationships despite improvements in PND (Tsivos et al. 2015). Mothers in the current study perceived some impact on confidence as a parent as with as relationships with their infants even if this was indirectly via improvements in mood. This observation may highlight the benefits of using qualitative methods to assess how therapy functions (Levitt et al. 2006). Mothers in this study appeared to differentiate between PND in which the mother-infant relationship was affected and PND in which the relationship was not affected. This finding is also novel and may offer insight into the equivocal findings reported in the literature, but further research using longitudinal designs is warranted to explore this concept more thoroughly.

\section{Changes to the infant}

Perceived changes to infants following therapy were mixed. Several mothers reported their infants appeared happier or more relaxed. However, many mothers did not notice any changes, and some acknowledged that it was difficult to identify changes to their babies due to their continuing development. The pattern of findings from the current study appears to mirror those reported by Cooper et al. (2003) who found that short-term improvements in maternal sensitivity were observed following improvement in PND, but not long-term effects on child development.
Yeah I think yeah, obviously it's hard cause with a baby they're changing all the time anyway so it could be, cause yeah he's a lot happier but that could just be because he's learning to smile more and things like that... but it could just be that he's noticing me smile more so it's that copying that he's noticing (Participant 4, group CBT).

\section{Views about parenting in therapy}

Participants were asked about including parent-related topics in therapy for PND, such as their identity as a mother and interactions with their infant. Most mothers reflected that their therapy had focused on mood rather than parenting, although they might have challenged thoughts about being a 'bad mother' in relation to mood. However, a small number of mothers also discussed parenting issues within therapy, such as ideas about interacting with and soothing their baby. Mothers' views on whether parentingrelated issues belonged in therapy for PND were mixed, identifying both advantages and disadvantages to including them.

\section{Views about parenting in therapy: advantages to including parenting in therapy}

Most of the mothers in the study believed that it was important for therapy for PND to focus on the mother's identity and confidence as a parent, identifying it as a key element and potential contributing factor to their depression. Many mothers reported they would have valued feedback or information about parenting to address their uncertainly in whether they were 'doing a good job', or ideas about interacting and bonding with their infant. Perceived inadequacy is a commonly reported theme for mothers with PND, including failing to meet idealised expectations of motherhood (Mollard 2014). A similar finding has been reported in a qualitative review of psychological and psychosocial interventions for PND: mothers who had received support from midwives did value feedback in relation to parenting (Hadfield and Wittkowski 2017). Furthermore, one mother believed that talking about the mother-babybond would normalise any difficulties women were experiencing in this regard:

Yeah it's very important 'cause postnatal depression is basically around the fact that you've had a baby. Otherwise it would just be depression, wouldn't it, so yeah it's very important to speak about the whole bond with a child cause if you have that... people probably don't admit to not having a bond, because they feel it's not, it's a bad thing to do to say well oh 
I've not been bonding with my baby. So to obviously speak about that and let them know that it is a normal thing (Participant 4, group CBT).

One mother also thought it was crucial that therapists and mental health professionals took the numerous challenges of parenting into consideration when working with mothers who experience PND.

Because it's massive and it's not just that your personal life is so encompassing, but parenting is just, it just takes over your life it's just so overwhelming especially in the newborn stage everything is about that so of course your mental health and any issues you have with it become about parenting and what it's like to live it day by day (Participant 9, individual EMDR).

\section{Views About Parenting in Therapy: Disadvantages to Including Parenting in Therapy}

One of the main disadvantages of including parentingrelated aspects in therapy was the risk of feeling criticised or judged as a parent, which would in turn exacerbate their mood difficulties. Feelings of inadequacy were a symptom of mothers' depression.

Somebody [with] postnatal depression could think oh no, they could easily think I'm not doing enough, I'm not good enough (Participant 3, individual CBT).

Sensitivity to criticism and self-criticism are well established to be important factors in depression more generally (Dinger et al. 2015). Many of the barriers women face in accessing therapy for PND in particular are related to stigma and worries about parental performance being scrutinised (Edwards and Timmons 2005).

Several of the mothers valued therapy for its focus on their own wellbeing and needs. Shifting the focus onto their parenting or their relationship with their child might therefore not fully meet their needs. The feeling of having 'disappeared' or losing one's identity after the birth of a child is a common experience for mothers (Beck 2002; Mollard 2014). In contrast, one of the key experiences of therapy for PND is reported to be the sense of feeling cared for (Myors et al. 2014).

I don't know if that's a universal feeling but I know for me that [focusing on parenting] would have been really terrible because one of the things that bothered me was how much I disappeared once I had [son] (Participant 9, individual EMDR).
Mothers who reported no changes to their relationship with their baby did not feel parenting support would be relevant for their circumstances.

It didn't really apply to me, because my anxieties were from having a baby but they weren't really connected, they weren't about my relationship with my child (Participant 13, group CBT).

Overall, the helpfulness of discussing parenting appeared to depend on it being presented in a safe and collaborative manner that normalised mothers' experiences.. These ideas reflect the key principles of a CBT approach (Beck et al. 1979), and so could feasibly be accommodated within this type of intervention. It was also important that therapy did not exclusively focus on parenting, and still addressed the mother's personal experiences and needs. These ideas support O'Hara and McCabe's suggestion (2013) that parenting interventions may need to be delivered separately to those focusing on mood, either in parallel or after depression treatment has finished, to give opportunity for mood to improve. Given that mothers in the current study attributed some of the potential for feeling criticised to the symptoms of depression, it may stand to reason that reducing these symptoms before starting to provide parenting support would circumvent these difficulties.

I think if you kind of interspersed it with different things kind of like with this is what you could potentially do to make yourself feel better or challenge some of your behaviours yeah that could work, but a standalone parenting thing I would have probably took quite badly (Participant 1, group CBT).

This study is one of the first to qualitatively explore mothers' views about the potential inclusion of parentingrelated support within an intervention for postnatal depression. Tsivos et al. (2014) reported that their pilot parenting intervention was rated as highly acceptable by mothers, which suggests that mothers did not feel criticised or neglected in the intervention. Nevertheless, it may be important that future therapies for PND which do include parenting elements are designed to minimise the risks of increasing perceived criticism or neglect the mothers' wellbeing.

\section{Discussion}

This study is one of the first to explore mothers' experiences of therapy offered within UK primary care mental health services for PND in depth with a specific focus on 
parenting-related outcomes and support. Overall, mothers described the therapy they received to be helpful and effective in treating their PND. Some of the experiences reported in the current study are comparable to the experiences of psychological therapy for depression more generally. However, certain aspects of the participants' experiences were clearly specific to the experience of PND: the therapeutic relationship was viewed as particularly important in light of the numerous relational challenges inherent in becoming a mother, such as increased isolation (Beck 2002; Mollard 2014). Acceptance of and normalising the mothers' experiences from both group members and therapists helped reduce the shame and stigma associated with PND (Edwards and Timmons 2005) and challenge societal pressures relating to the concept of the ideal mother (Henderson et al. 2016). Furthermore, childcare was a particular aspect of therapy which could either facilitate or hinder engagement in therapy. Mothers found the cognitivebehavioural approach helpful in addressing symptoms of PND and reported that their confidence as parents increased and they no longer believed they were a 'bad mother'. Parenting support was viewed as potentially useful in improving knowledge and confidence, provided it was collaborative and their own needs were central to therapy. There were, however, some potential disadvantages, in particular mothers feeling criticised. The findings will be pertinent for the further development of perinatal mental health services, especially within the UK (NICE 2014; NHS England 2018).

Qualitative methods as used in the present study provide appropriate means to develop understandings of key processes within psychological therapy (Levitt et al. 2006) and offer opportunities for service users' perspectives to be an integral part of clinical decision making processes (Hodgetts and Wright 2007). However, one potential limitation of this study is that there was variability in the therapy offered across different mental health services, including both individual and group-based interventions. This may mean that experiences inherent to each format were not explored sufficiently, or that intrinsically different experiences were combined. However, this approach reflected the real make-up of UK mental health service provision related to PND in primary care. Additionally, it allowed for similarities and differences between group and individual formats to be identified; for example, both groups of participants valued thought challenging and experienced the ending of therapy as significant.

Furthermore, depression scores (and therefore indicators of PND severity) were not obtained. However, having been accepted into primary care mental health services, it was concluded that the participants would have undergone a thorough psychological assessment by a qualified mental health professional. In addition to this, qualitative approaches prioritise the views of the participants rather than quantitative ratings or scores (Levitt et al. 2006).

Finally, all the participants were of White British ethnicity. Concepts relevant to mothers from different cultural backgrounds were perhaps not represented in the analysis. For example, immigrant mothers and mothers of Black and Minority Ethnic (BAME) background often experience further challenges in accessing mental health services for postnatal depression (National Institute for Mental Health in England 2003; Wittkowski et al. 2017). Although the current study was open to mothers of all ethnicities, recruitment strategies could have been tailored more effectively to facilitate BAME mothers' participation.

The findings of the current study have important implications for future research into psychological interventions offered to women with PND. The results suggested that there were certain aspects of psychological therapy for PND that were particularly pertinent for the engagement of mothers with a new infant. Research into future interventions for PND should take into consideration the impact of minimising barriers, such as childcare and PND-related stigma. The findings in our study relating to the changes reported in maternal cognitions warrant further exploration, and future research would benefit from investigating the impact of therapy on maternal guilt and shame more thoroughly. It would also be important to take into account the societal pressures and ideals around being the 'perfect mother' in this regard.

Additionally, the current study adds to the growing literature around parenting interventions as part of treatment of PND, and we suggest that the addition of tailored parenting support as well as or alongside a psychological therapy should be explored in future research. Interventions exist that combine psychological therapeutic principles with parenting support, such as Baby Triple P (Sanders 2012). This approach has been reported to be acceptable to mothers with PND (Tsivos et al. 2014), but its evidence base is still developing (e.g., see Wittkowski et al. 2018; Henderson et al. 2019). Given the limitations of this study, we also suggest that further research explores the specific experiences of particular therapeutic interventions, such as CBT, for PND. Finally, although group and individual therapy have been found to have similar cost effectiveness (Radhakrishnan et al. 2013), the current results identified that the group format conferred additional benefits in terms of providing additional social support and normalising from other mothers. It would be important to assess the effectiveness for group therapy for PND against the current evidence base for individual therapy for PND.

Acknowledgements The authors gratefully acknowledge the involvement of the service users and mothers who dedicated their time and shared their experiences for this study. The authors also acknowledge 
the support from mental health clinicians in various NHS trusts, in particular the invaluable support from Joanne Gisbourne and Dr Catherine Houseman.

Author Contributions H.H.: designed and executed the study, completed analyses of data, and wrote the paper. P.B.: assisted with data analysis and collaborated in editing the manuscript. S.G.: collaborated with the design of the study and assisted in recruitment of participants. A.W.: developed the original idea for this study and oversaw all aspects of it, including finalising all drafts of this paper.

\section{Compliance with Ethical Standards}

Conflict of Interest The authors declare that they have no conflict of interest.

Ethical Approval This study obtained all relevant NHS and University of Manchester ethical, HRA and R\&I approvals (NHS REC ID: 194202; UREC ID: 2016-0256-119).

Informed Consent In accordance with research ethics principles, all participants gave full informed consent to participate in the research. The consent form used in the study was approved by all relevant ethical bodies.

Publisher's note Springer Nature remains neutral with regard to jurisdictional claims in published maps and institutional affiliations.

Open Access This article is distributed under the terms of the Creative Commons Attribution 4.0 International License (http://crea tivecommons.org/licenses/by/4.0/), which permits unrestricted use, distribution, and reproduction in any medium, provided you give appropriate credit to the original author(s) and the source, provide a link to the Creative Commons license, and indicate if changes were made.

\section{References}

Ahn, H. N., \& Wampold, B. E. (2001). Where oh where are the specific ingredients? A meta-analysis of component studies in counselling and psychotherapy. Journal of Counselling Psychology, 48(3), 251-257. https://doi.org/10.1037//O022-OI67.48. 3.251 .

Barnes, M., Sherlock, S., Thomas, L., Kessler, D., Kuyken, W., OwenSmith, A., \& Turner, K. (2013). No pain, no gain: depressed clients' experiences of cognitive behavioural therapy. British Journal of Clinical Psychology, 52(4), 347-364. https://doi.org/ 10.1111/bjc. 12021.

Bauer, A., Parsonage, M., Knapp, M., Iemmi, V., \& Adelaja, B. (2015). The costs of perinatal mental health problems. London: London School of Economics Personal Social Services Research Unit, Centre for Mental Health.

Beck, A. T., Rush, A. J., Shaw, B. F., \& Emery, G. (1979). Cognitive therapy of depression. New York: Guilford Press.

Beck, C. T. (2002). Postpartum depression: a metasynthesis. Qualitative Health Research, 12(4), 453-472.

Berger, R. (2015). Now I see it, now I don't: researcher's position and reflexivity in qualitative research. Qualitative Research, 15(2), 219-234. https://doi.org/10.1177/1468794112468475.

Bilzsta, J., Eriksen, J., Buist, A., \& Milgrom, J. (2010). Women's experiences of postnatal depression - beliefs and attitudes as barriers to care. Australian Journal of Advanced Nursing, 27(3), $44-54$.
Braun, V., \& Clarke, V. (2006). Using thematic analysis in psychology. Qualitative Research in Psychology, 3(2), 77-101.

Bower, P., \& Gilbody, S. (2005). Stepped care in psychological therapies: access, effectiveness and efficiency. The British Journal of Psychiatry, 186(1), 11-17. https://doi.org/10.1192/bjp.186.1.11.

Butler, H., Hare, D., Walker, S., Wieck, A., \& Wittkowski, A. (2014). The acceptability and feasibility of the baby triple $\mathrm{P}$ positive parenting programme on a mother and baby unit: Q-methodology with mothers with severe mental illness. Archives of Women's Mental Health, 17(5), 455-463. https://doi.org/10.1007/s00737014-0429-4.

Cooke, S., Smith, I., Turl, E., \& Arnold, E. (2012). Parent perspectives of clinical psychology access when experiencing distress. Community Practitioner, 85(4), 34-47.

Cooper, P. J., Murray, L. \& Halligan, S. L. (2010). Treatment of postpartum depression. In: R. Tremblay, R. Barr, R. Peters, \& M. Boivin (Eds), Encyclopedia on early childhood development. Montreal, Quebec: Centre of Excellence for Early Childhood Development.

Cooper, P. J., Murray, L., Wilson, A., \& Romaniuk, H. (2003). Controlled trial of the short-and long-term effect of psychological treatment of post-partum depression. The British Journal of Psychiatry, 182(5), 412-419. https://doi.org/10.1192/bjp.182.5. 412.

Cornish, A., McMahon, C., \& Ungerer, J. (2008). Postnatal depression and the quality of mother-infant interactions during the second year of life. Australian Journal of Psychology, 60(3), 142-151. https://doi.org/10.1080/00049530701477738.

Cuijpers, P., Brännmark, J., \& van Straten, A. (2008). Psychological treatment of postpartum depression: a meta-analysis. Journal of Clinical Psychology, 64(1), 103-118. https://doi.org/10.1002/ jclp.20432.

Davies, S., \& Jasper, M. (2004). A first-stage evaluation of a group programme for PND. Community Practitioner, 77(11), 426-433.

Department of Health. (2016). Five year forward view for mental health. England: Independent Mental Health Task Force.

Dennis, C. L., \& Hodnett, E. D. (2007). Psychosocial and psychological interventions for treating postpartum depression. The Cochrane Database of Systematic Reviews, 4, Art. No.: CD006116. https://doi.org/10.1002/14651858.CD006116.pub2.

Dennis, C. L., \& Letourneau, N. (2007). Global and relationshipspecific perceptions of support and the development of postpartum depressive symptomatology. Social Psychiatry and Psychiatric Epidemiology, 42(5), 389-395. https://doi.org/10.1007/ s00127-007-0172-5.

Dennis, C. L., Hodnett, E., Kenton, L., Weston, J., Zupancic, J., Stewart, D. E., \& Kiss, A. (2009). Effect of peer support on prevention of postnatal depression among high risk women: multisite randomised controlled trial. British Medical Journal, 338, 30-64. https://doi.org/10.1136/bmj.a3064.

Dennis, C., \& Chung-Lee, L. (2006). Postpartum depression helpseeking barriers and maternal treatment preferences: a qualitative systematic review. Birth, 33(4), 323-331. https://doi.org/10.1111/ j.1523-536x.2006.00130.x

Dennis, C.-L. (2017). Psychological treatment is one of the several important components to the effective management of postpartum depression. Evidence Based Nursing, 20(1), 8-10. https://doi.org/ 10.1136/eb-2016-102521.

Dinger, U., Barrett, M. S., Zimmermann, J., Schauenburg, H., Wright, A. G., Renner, F., \& Barber, J. P. (2015). Interpersonal problems, dependency, and self-criticism in major depressive disorder. Journal of Clinical Psychology, 71(1), 93-104. https://doi.org/10. $1002 /$ jclp. 22120.

Edwards, E., \& Timmons, S. (2005). A qualitative study of stigma among women suffering postnatal illness. Journal of Mental Health, 14(5), 471-481. https://doi.org/10.1080/09638230500271097. 
Farabaugh, A., Fisher, L., Nyer, M., Holt, D., Cohen, M., Baer, L., \& Alpert, J. E. (2015). Similar changes in cognitions following cognitive-behavioral therapy or escitalopram for major depressive disorder: implications for mechanisms of change. Annals of Clinical Psychiatry, 27(2), 118-126.

Furber, C. (2010). Framework analysis: a method for analysing qualitative data. African Journal of Midwifery and Women's Health, 4(2), 97-100. https://doi.org/10.12968/ajmw.2010.4.2.47612.

Gale, N. K., Heath, G., Cameron, E., Rashid, S., \& Redwood, S. (2013). Using the framework method for the analysis of qualitative data in multi-disciplinary health research. BMC Medical Research Methodology, 13(1), 117 https://doi.org/10.1186/14712288-13-117.

Goodman, J. H. (2009). Women's attitudes, preferences, and perceived barriers to treatment for perinatal depression. Birth, 36(1), 60-69. https://doi.org/10.1111/j.1523-536X.2008.00296.x.

Hadfield, H. L., \& Wittkowski, A. (2017). Mothers' experiences of seeking and receiving psychological and psychosocial interventions for postnatal depression: a systematic review and thematic synthesis of the qualitative literature. Journal of Midwifery and Women's Health, 62(6), 723-736. https://doi.org/10.1111/jmwh. 12669.

Henderson, A., Harmon, S., \& Newman, H. (2016). The price mothers pay, even when they are not buying it: mental health consequences of idealized motherhood. Sex Roles, 74(11-12), 512-526. https://doi.org/10.1007/s11199-015-0534-5.

Henderson, M., Wittkowski, A., McIntosh, E., McConnachie, A., Buston, K., Wilson, P., \& Law, J. (2019). Trial of healthy relationship initiatives for the very early years (THRIVE), evaluating Enhanced Triple $\mathrm{P}$ for Baby and Mellow Bumps additional social and care needs during pregnancy and their infants who are at higher risk of maltreatment: study protocol for a randomised controlled trial. Trials, 20(1), 1-15.

Hipwell, A. E., Goossens, F. A., Melhuish, E. C., \& Kumar, R. (2000). Severe maternal psychopathology and infant-mother attachment. Developmental Psychopathology, 12, 157-175.

Hodgetts, A., \& Wright, J. (2007). Researching clients' experiences: a review of qualitative studies. Clinical Psychology \& Psychotherapy, 14(3), 157-163.

Junge, C., Garthus-Niegel, S., Slinning, K., Polte, C., Simonsen, T. B., \& Eberhard-Gran, M. (2017). The impact of perinatal depression on children's social-emotional development: a longitudinal study. Maternal and Child Health Journal, 1-9. https://doi.org/10.1007/ s10995-016-2146-2.

Kivlighan, Jr. D. M., \& Mullison, D. (1988). Participants' perception of therapeutic factors in group counseling: the role of interpersonal style and stage of group development. Small Group Behavior, 19(4), 452-468. 10.1.1.907.1111.

Lambert, M. J., \& Barley, D. E. (2001). Research summary on the therapeutic relationship and psychotherapy outcome. Psychotherapy: Theory, Research, Practice, Training, 38(4), 357 https://doi.org/10.1037//0033-3204.38.4.357.

Letourneau, N. L., Dennis, C. L., Benzies, K., Duffett-Leger, L., Stewart, M., Tryphonopoulos, P. D., \& Watson, W. (2012). Postpartum depression is a family affair: addressing the impact on mothers, fathers, and children. Issues in Mental Health Nursing, 33(7), 445-457. https://doi.org/10.3109/01612840.2012.673054.

Levitt, H., Butler, M., \& Hill, T. (2006). What clients find helpful in psychotherapy: developing principles for facilitating moment-tomoment change. Journal of Counseling Psychology, 53(3), 314 https://doi.org/10.1037/0022-0167.53.3.314.

Liss, M., Schiffrin, H. H., \& Rizzo, K. M. (2013). Maternal guilt and shame: the role of self-discrepancy and fear of negative evaluation. Journal of Child and Family Studies, 22(8), 1112-1119. https://doi.org/10.1007/s10826-012-9673-2.
Lovejoy, M. C., Graczyk, P. A., O’Hare, E., \& Neuman, G. (2000). Maternal depression and parenting behavior: a meta-analytic review. Clinical Psychology Review, 20(5), 561-592.

McLoughlin, J. (2013). Stigma associated with postnatal depression: a literature review. British Journal of Midwifery, 21(11), 784-791. https://doi.org/10.12968/bjom.2013.21.11.784.

Megnin-Viggars, O., Symington, I., Howard, L. M., \& Pilling, S. (2015). Experience of care for mental health problems in the antenatal or postnatal period for women in the UK: A systematic review and meta-synthesis of qualitative research. Archives of Women's Mental Health, 18(6), 745-759. https://doi.org/10. 1007/s00737-015-0548-6.

Mohr, D. C., Ho, J., Duffecy, J., Baron, K. G., Lehman, K. A., Jin, L., \& Reifler, D. (2010). Perceived barriers to psychological treatments and their relationship to depression. Journal of Clinical Psychology, 66(4), 394-409. https://doi.org/10.1002/jclp.20659.

Mollard, E. K. (2014). A qualitative meta-synthesis and theory of postpartum depression. Issues in Mental Health Nursing, 35(9), 656-663. https://doi.org/10.3109/01612840.2014.893044.

Myors, K., Schmied, V., Johnson, M., \& Cleary, M. (2014). 'My special time': Australian women's experiences of accessing a specialist perinatal and infant mental health service. Health and Social Care in the Community, 22(3), 268-277. https://doi.org/ 10.1111/hsc. 12079 .

National Institute for Mental Health in England (2003). Inside out: improving mental health services for black and minority ethnic communities in England. London: National Institute for Mental Health in England.

National Institute of Health and Care Excellence [NICE]. (2014). Antenatal and postnatal mental health: clinical management and service guidance [CG192]. England: National Institute of Health and Care Excellence.

NHS England (2018). The perinatal mental health care pathways. https://www.england.nhs.uk/wp-content/uploads/2018/05/perina tal-mental-health-care-pathway.pdf.

Nilsson, T., Svensson, M., Sandell, R., \& Clinton, D. (2007). Patients' experiences of change in cognitive-behavioral therapy and psychodynamic therapy: a qualitative comparative study. Psychotherapy Research, 17(5), 553-566. https://doi.org/10.1080/ 10503300601139988.

Noyce, R., \& Simpson, J. (2016). The experience of forming a therapeutic relationship from the client's perspective: a metasynthesis. Psychotherapy Research, 1-16. https://doi.org/10.1080/ 10503307.2016.1208373.

Nylen, K. J., Moran, T. E., Franklin, C. L., \& O’Hara, M. W. (2006). Maternal depression: a review of relevant treatment approaches for mothers and infants. Infant Mental Health Journal, 27(4), 327-343. https://doi.org/10.1002/imhj.20095.

O'Hara, M., \& McCabe, J. (2013). Postpartum depression: current status and future directions. Annual Review of Clinical Psychology, 9(1), 379-407. https://doi.org/10.1146/annurev-clinpsy050212-185612.

O'Hara, M. W., Wisner, K. L., \& Asher, H. (2014). Perinatal mental illness: Definition, description and aetiology. Best Practice \& Research Clinical and Gynaecology, 28, 3-11. https://doi.org/10. 1016/j.bpobgyn.2013.09.002.

O’Mahen, H. A., \& Flynn, H. A. (2008). Preferences and perceived barriers to treatment for depression during the perinatal period. Journal of Women's Health, 17(8), 1301-1309. https://doi.org/ 10.1089/jwh.2007.0631.

O'Mahen, H., Fedock, G., Henshaw, E., Himle, J. A., Forman, J., \& Flynn, H. A. (2012). Modifying CBT for perinatal depression: what do women want? A qualitative study. Cognitive and Behavioral Practice, 19(2), 359-371.

Radhakrishnan, M., Hammond, G., Jones, P. B., Watson, A., McMillan-Shields, F., \& Lafortune, L. (2013). Cost of improving access 
to psychological therapies (IAPT) programme: an analysis of cost of session, treatment and recovery in selected primary care trusts in the East of England region. Behaviour Research and Therapy, 51(1), 37-45. https://doi.org/10.1016/j.brat.2012.10.001.

Righetti-Veltema, M., Bousquet, A., \& Manzano, J. (2003). Impact of postpartum depressive symptoms on mother and her 18-monthold infant. European Child \& Adolescent Psychiatry, 12(2), 75-83. https://doi.org/10.1007/s00787-003-0311-9.

Ritchie, J., \& Spencer, L. (1994). Analyzing qualitative data. In: A. Bryman \& R. G. Burgess (Eds), Qualitative data analysis for applied policy research (pp.173-194). London: Routledge

Sanders, M. R. (2012). Development, evaluation, and multinational dissemination of the triple P-positive parenting program. Annual Review of Clinical Psychology, 8, 345-379. https://doi.org/10. 1146/annurev-clinpsy-032511-143104.

Scope, A., Booth, A., \& Sutcliffe, P. (2012). Women's perceptions and experiences of group cognitive behaviour therapy and other group interventions for postnatal depression: a qualitative synthesis. Journal of Advanced Nursing, 68(9), 1909-1919. https://doi.org/ 10.1111/j.1365-2648.2012.05954.x.

Scope, A., Leaviss, J., Kaltenthaler, E., Parry, G., Sutcliffe, P., Bradburn, M., \& Cantrell, A. (2013). Is group cognitive behaviour therapy for postnatal depression evidence-based practice? A systematic review. BMC Psychiatry, 13(1), $321 \mathrm{https} / / /$ doi.org/10. 1186/1471-244X-13-321.

Slade, P., Morrell, C. J., Rigby, A., Ricci, K., Spittlehouse, J., \& Brugha, T. S. (2010). Postnatal women's experiences of management of depressive symptoms: a qualitative study. British Journal of General Practice, 60(580), e440-e448. https://doi.org/ 10.3399/bjgp10X532611.

Stephens, S., Ford, E., Paudyal, P., \& Smith, H. (2016). Effectiveness of psychological interventions for postnatal depression in primary care: a meta-analysis. The Annals of Family Medicine, 14(5), 463-472. https://doi.org/10.1370/afm.1967.

Straarup, N. S., \& Poulsen, S. (2015). Helpful aspects of metacognitive therapy and cognitive behaviour therapy for depression: a qualitative study. The Cognitive Behaviour Therapist, 8, 22-30. https://doi.org/10.1017/S1754470X15000574.

Tsivos, Z. L., Calam, R., Sanders, M. R., \& Wittkowski, A. (2014). A pilot randomized controlled trial to evaluate the feasibility and acceptability of the baby triple $\mathrm{P}$ positive parenting programme in mothers with postnatal depression. Clinical Child Psychology and Psychiatry, 20(4), 532-554.

Tsivos, Z. L., Calam, R., Sanders, M. R., \& Wittkowski, A. (2015). Interventions for postnatal depression assessing the mother-infant relationship and child developmental outcomes: a systematic review. International Journal of Women's Health, 7, 429 https:// doi.org/10.2147/IJWH.S75311.

van Doesum, K., Hosman, C., Riksen-Walraven, J., \& Hoefnagals, C. (2007). Correlates of depressed mothers' sensitivity toward their infants: the role of maternal, child, and contextual characteristics. Journal of the American Academy of Child and Adolescent Psychiatry, 46(6), 747-756. https://doi.org/10. 1097/chi.0b013e318040b272.

Ward, D. J., Furber, C., Tierney, S., \& Swallow, V. (2013). Using framework analysis in nursing research: a worked example. Journal of Advanced Nursing, 69(11), 2423-2431. https://doi. org/10.1111/jan.12127.

Wittkowski, A., Cartwright, K., Emsley, R., Bee, P., Camacho, E., Calam, R., Cross, C., \& Reid, H. (2018). Enhancing maternal and infant wellbeing: study protocol for a feasibility trial of the baby triple $\mathrm{P}$ positive parenting programme for mothers with severe mental health difficulties (the IMAGINE study). Trials, 19(1), 479.

Wittkowski, A., Patel, S., \& Fox, J. R. (2017). The experience of postnatal depression in immigrant mothers living in western countries: a meta-synthesis. Clinical Psychology and Psychotherapy, 24(2), 411-427. https://doi.org/10.1002/cpp.2010.

Yalom, I. D. (1995). The theory and practice of group psychotherapy (4th ed.). New York: Basic Books. 